\title{
Microstructure Evolution of a Medium Manganese Steel During Thermomechanical Processing
}

\author{
BINHAN SUN, HUSEYIN AYDIN, FATEH FAZELI, and STEPHEN YUE
}

\begin{abstract}
An as-cast $\mathrm{Fe}-0.2 \mathrm{C}-10 \mathrm{Mn}-3 \mathrm{Si}-3 \mathrm{Al}$ medium manganese steel with a ferrite plus austenite duplex microstructure was subjected to hot compression tests at deformation temperatures within two-phase $(\alpha+\gamma)$ range and various strain rates. The microstructure evolution of the experimental steel during hot deformation was investigated. The flow curves were characterized by a discontinuous yielding at the beginning of plastic deformation, followed by a weak work hardening to a peak and a subsequent mild softening stage. Two restoration processes took place during hot deformation, namely dynamic recrystallization (DRX) of austenite and continuous dynamic recrystallization of ferrite. The DRX of austenite was believed to dominate the softening stage of the flow curves. The discontinuous yielding stemmed from the existing Kurdjumov-Sachs (K-S) orientation relationship between ferrite and austenite in the initial undeformed microstructure, which gradually weakened during subsequent deformation.
\end{abstract}

DOI: $10.1007 / \mathrm{s} 11661-016-3338-5$

(C) Published with permission of the Crown in Right of Canada 2016

\section{INTRODUCTION}

THE desire for weight reduction, enhanced fuel economy and improved safety in automobile industry has led to the development of new generations of advanced high strength steels (AHSS). Currently, third-generation (3rd Gen) AHSS which is expected to surpass the strength-ductility combination of first-generation AHSS at a lower cost than second-generation AHSS, has attracted considerable attention. ${ }^{[1]}$ Medium Mn steels (containing approximately 3 to $12 \mathrm{wt}$ pct $\mathrm{Mn}$ ) are considered as a strong contender for 3rd Gen AHSS due to high fraction of retained austenite. ${ }^{[2,3]}$ The stability and properties of this austenite can be tailored readily by $\mathrm{Mn}$ content and partitioning of alloying elements during intercritical stage without a need for subsequent bainite overaging or martensite quenching-partitioning. Aluminum and silicon are also added to medium Mn steels for suppressing cementite precipitation and adjusting the stacking fault energy (SFE) of the retained austenite. ${ }^{[4,5]}$ However, increasing amount of $\mathrm{Al}$ and $\mathrm{Si}$ expands the two-phase $(\alpha+\gamma)$ range of medium Mn steels, ${ }^{[6,7]}$ thus increasing the complexity in

BINHAN SUN, Graduate Student, and STEPHEN YUE, Professor, are with the Department of Materials Engineering, McGill University, 3610 University St., Montreal, QC, Canada. Contact e-mail: binhan.sun@mail.mcgill.ca HUSEYIN AYDIN, formerly Postdoctoral Researcher with the Department of Materials Engineering, McGill University, is now Senior Researcher with the TUBITAK Marmara Research Center, Materials Institute, Gebze, Turkey. FATEH FAZELI, Research Scientist, is with the CanmetMATERIALS, Natural Resources Canada, 183 Longwood Rd S, Hamilton, ON, L8P 0A5, Canada.

Manuscript submitted June 28, 2015.

(C) Published with permission of the Crown in Right of Canada pertains to F. Fazeli.

Article published online January 21, 2016 thermomechanical processing if hot working in the two-phase region cannot be avoided.

Dynamic recovery (DRV) and dynamic recrystallization (DRX) are the two softening (restoration) mechanisms in metallic materials during high temperature deformation. ${ }^{[8]}$ In ferritic steels with a high SFE, DRV is favored because dislocation climb and cross-slip occur easily, although it was found by several researchers that DRX could also prevail under certain conditions in ferrite. ${ }^{[9-12]}$ A typical DRV flow curve is characterized by a monotonic work hardening followed by a steady-state plateau which is achieved by the balance between dislocation generation and annihilation. During the DRV process, a microstructure with low angle boundary subgrains develops. However, in a low SFE material such as austenitic steels, DRV is hindered due to the difficulty in climb and cross-slip of dislocations, thus DRX occurs when a critical driving force or strain is achieved. This process is generally characterized by one or several broad work hardening peaks in the true stress-strain curve, followed by a softening and a steady state. ${ }^{[8,13,14]}$ When materials are deformed at a temperature within two-phase $(\alpha+\gamma)$ range, the restoration kinetics of each phase can be influenced by the deformation heterogeneity of ferrite and austenite. Researchers have found that ferrite underwent continuous dynamic recrystallization (extended dynamic recovery) in duplex stainless steels under hot deformation. ${ }^{[14-16]}$ With regard to austenite, some authors proposed that the DRX of austenite could be delayed or even inhibited in duplex stainless steels. ${ }^{[17-19]}$

Although medium Mn steels are gaining an increasing attention, the scope of research is mainly focused on microstructure-property relationship of hot-rolled or cold-rolled products. There are very few published data available on the thermomechanical behavior of this class of steel, especially for those with high $\mathrm{Al} / \mathrm{Si}$ content 
which possess a large two-phase range. In this work, an as-cast $10 \mathrm{wt}$ pct $\mathrm{Mn}$ steel with $3 \mathrm{wt}$ pct $\mathrm{Al}$ and $3 \mathrm{wt}$ pct Si was selected and hot compressed at various temperatures and strain rates. The purpose of the current study is to investigate the thermomechanical behavior and the microstructure evolution of the steel during hot deformation in two-phase ferrite-austenite domain.

\section{EXPERIMENTAL PROCEDURE}

The chemical composition of the experimental steel is given in Table I. Hot compression tests were conducted with a Gleeble 3800 thermomechanical simulator and a Bahr DIL805 deformation dilatometer at CanmetMATERIALS laboratory, Hamilton, Ontario. The cylindrical specimens with length to diameter ratio of $3: 2(15 \times 10 \mathrm{~mm}$ for Gleeble, $9 \times 6 \mathrm{~mm}$ for the deformation dilatometer), were machined from the as-cast material. Before hot deformation testing, the specimens were homogenized at $1473 \mathrm{~K}\left(1200^{\circ} \mathrm{C}\right)$ for 3 hours and water quenched to room temperature.

The schedule of the hot compression tests is shown in Figure 1(a). The reheating was performed at $1473 \mathrm{~K}$ $\left(1200{ }^{\circ} \mathrm{C}\right)$ for 30 second, followed by cooling to the deformation temperatures and holding for 30 second to homogenize temperature. Additional samples were quenched in order to determine the microstructure immediately before hot compression. The compression tests were carried out at a temperature ranging from $1173 \mathrm{~K}$ to $1373 \mathrm{~K}\left(900{ }^{\circ} \mathrm{C}\right.$ to $\left.1100{ }^{\circ} \mathrm{C}\right)$ and strain rate from 0.01 to $10 \mathrm{~s}^{-1}$ at intervals of an order of magnitude. Hot compressed samples were also quenched in order to retain the deformed microstructure to room temperature.

Hot torsion tests were carried out in Hot Deformation Laboratory at McGill University, with a servohydraulic MTS hot torsion machine equipped with a radiation furnace. The schedule is shown in Figure 1(b). Torsion specimens with $22.2 \mathrm{~mm}$ gauge length and $6.35 \mathrm{~mm}$ diameter were machined and subjected to hot torsion tests at the temperature of $1273 \mathrm{~K}\left(1000{ }^{\circ} \mathrm{C}\right)$ and strain rate of $1 \mathrm{~s}^{-1}$ for 3 passes with 5 seconds interpass time. A longer holding time at the reheating temperature $\left[1473 \mathrm{~K}\left(1200^{\circ} \mathrm{C}\right)\right]$ and before hot deformation in torsion tests was used, in order to ensure adequate homogenization of temperature in the radiation furnace.

Microstructure characterization was performed with a Nikon Epiphot 200 optical microscopy (OM) and a Hitachi SU3500 scanning electron microscopy (SEM) equipped with an electron backscattered diffraction (EBSD) detector. Samples for metallographic examination were etched by 2 pct nital followed by $10 \mathrm{pct}$ aqueous sodium metabisulfite $\left(\mathrm{Na}_{2} \mathrm{~S}_{2} \mathrm{O}_{5}\right)$. For EBSD observation, samples were finally polished by $0.5 \mu \mathrm{m}$ colloidal silica for 4 to 8 hours in a vibratory polisher.

\section{RESULTS}

\section{A. Mechanical Behavior}

Flow curves of the experimental steel at different deformation temperatures and strain rates are shown in Figure 2. It is well established and clearly seen that the flow stress increases with decreasing temperatures and increasing strain rates. All the curves show a similar behavior, which can be characterized by a discontinuous yielding (1st part), followed by a mild working hardening to a peak (2nd part) and a subsequent weak softening stage (3rd part).

In order to determine the combined effect of temperature and strain rate on the flow curve characteristics, the Zener-Hollomon parameter ( $\mathrm{Z}$ ) was calculated based on the generalized hyperbolic sine function proposed by Sellars and Tegart ${ }^{[16,20]}$ :

$$
Z=\dot{\varepsilon} \cdot \exp \left(\frac{Q}{R T}\right)=A\{\sinh (\alpha \sigma)\}^{n},
$$

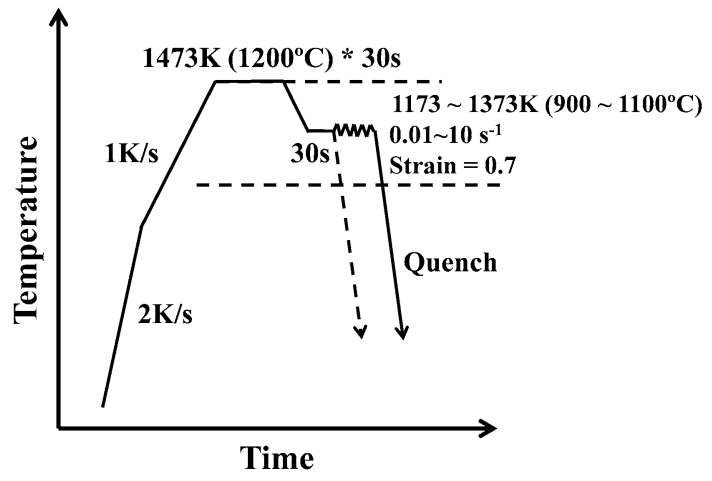

(a)

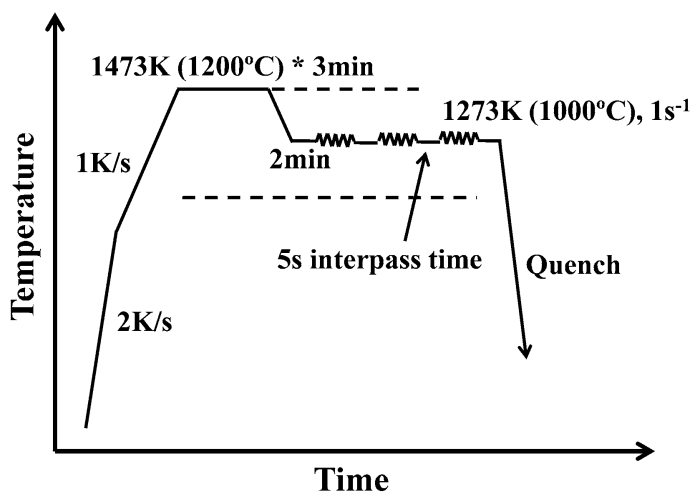

(b)

Fig. 1-Time-temperature schedule of $(a)$ hot compression tests and (b) hot torsion tests.

Table I. Steel Composition in Weight Percent

\begin{tabular}{lcccccr}
\hline Alloy & $\mathrm{C}$ & $\mathrm{Mn}$ & $\mathrm{Al}$ & $\mathrm{Si}$ & Mo & Fe \\
\hline 10Mn steel, as-cast & 0.20 & 10.02 & 3.17 & 3.19 & 0.06 & balance \\
\hline
\end{tabular}




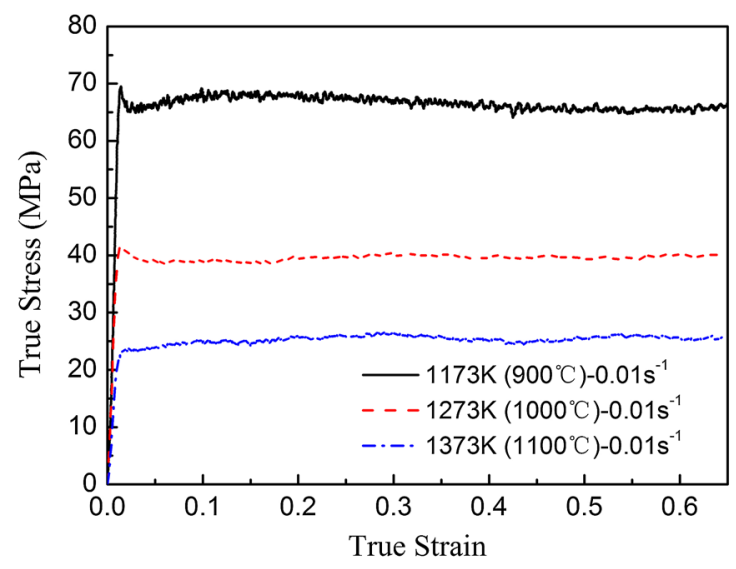

(a)

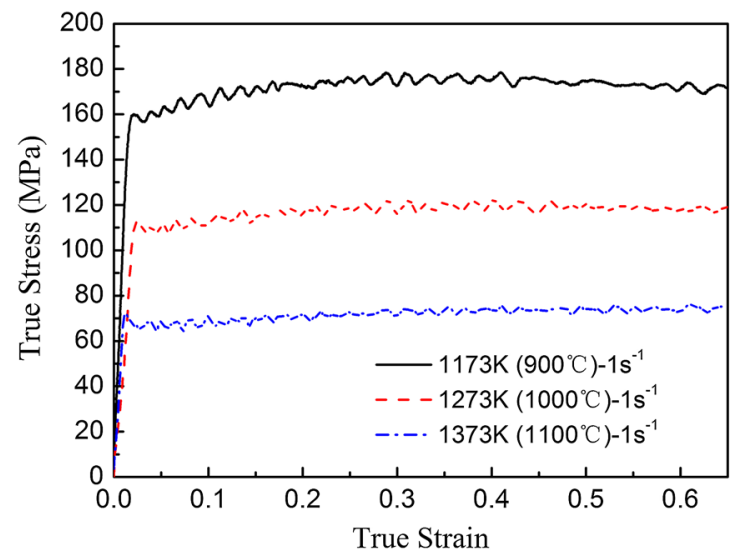

(c)

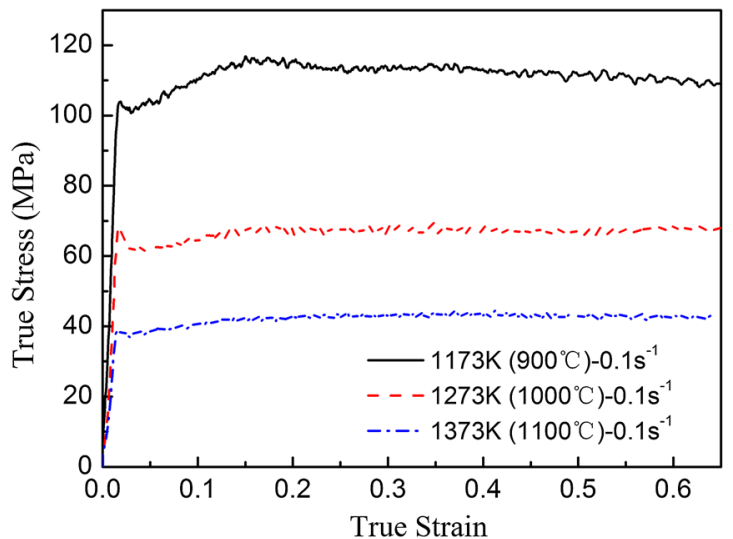

(b)

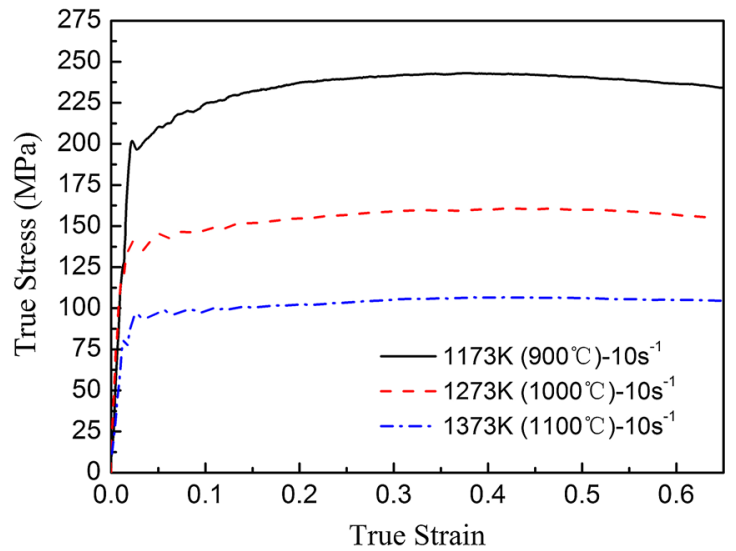

(d)

Fig. 2-Hot compression flow curves of the as-cast medium Mn steel: (a) $0.01 \mathrm{~s}^{-1} ;(b) 0.1 \mathrm{~s}^{-1} ;(c) 1 \mathrm{~s}^{-1} ;(d) 10 \mathrm{~s}^{-1}$.

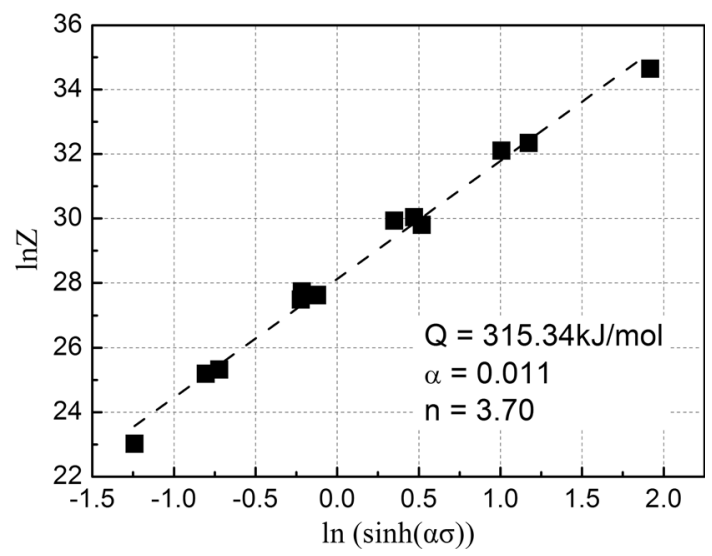

Fig. 3-The relationship between $\mathrm{Z}$ parameter and peak stress.

where $\dot{\varepsilon}$ is the strain rate; $Q$ is the activation energy of deformation at high temperatures; $\sigma$ was selected as the peak stress in this study; $R, A, \alpha, n$ are constants. Figure 3 shows the final calculation result, where a linear relationship between $\ln Z$ and $\ln [\sinh (\alpha \sigma)]^{n}$ exists, with a linear correlation coefficient of 0.995 . The activation energy $(Q)$ is determined as $315.34 \mathrm{~kJ} / \mathrm{mol}$, which is lower than that in duplex stainless steels (350 to $\left.580 \mathrm{~kJ} / \mathrm{mol}^{[14,21]}\right)$ but similar to reported values for $\mathrm{C}-\mathrm{Mn}$ and microalloyed steels (230 to $390 \mathrm{~kJ} / \mathrm{mol}^{[22]}$ ).

The average rate of work hardening $(\overline{d \sigma / d \varepsilon})$ in the 2nd part of the flow curves was determined to quantify the extent of work hardening. Most of the measured flow curves followed a linear work hardening during the second part (Figure 2), as such a linear regression was made and the slope of the fitted line was considered as the average rate of work hardening. It was plotted as a function of $\ln (Z)$ which increases with decreasing temperatures and increasing strain rates. As shown in Figure 4, the work hardening rate generally increases with higher $Z$, which basically makes the peaks of the flow curves become more pronounced at lower temperatures and higher strain rates.

\section{B. Microstructure}

Figure 5 shows the microstructure of the as-cast medium Mn steel after homogenization at $1473 \mathrm{~K}$ $\left(1200{ }^{\circ} \mathrm{C}\right)$ for 3 hours followed by water quench. A ferrite plus austenite duplex (FADP) microstructure with austenite volume fraction of around 45 pct was characterized at room temperature. The microstructure is believed to be retained from the homogenization temperature since very less austenite-ferrite transformation 


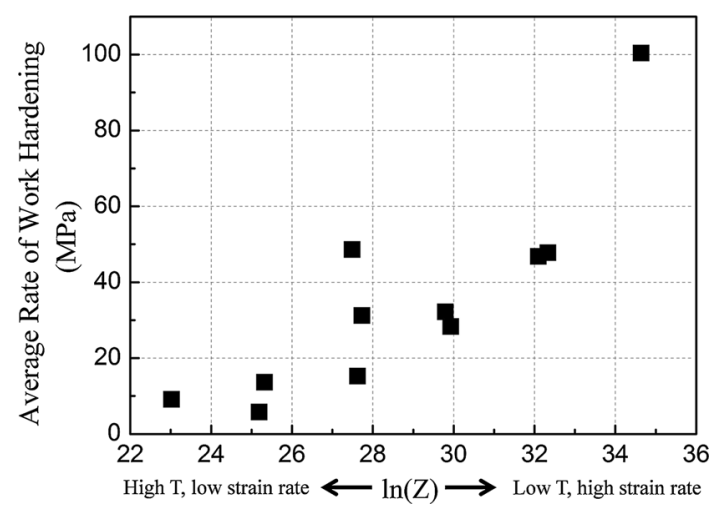

Fig. 4-The effect of hot deformation temperature and strain rate on the rate of work hardening in the 2 nd part of the flow curves.

could occur during water quenching. Austenite has a dendritic structure and is located on the boundaries of ferrite or within ferrite grains. Figure 6 gives the austenite fraction of the specimens quenched from different temperatures before deformation. It is found that the material has a similar starting microstructure before hot deformation for all the examined temperatures, indicating that no phase transformation occurs during the cooling from reheating temperature to hot deformation temperatures. This could also explain the linear relationship between $\ln Z$ and $\ln [\sinh (\alpha \sigma)]^{n}$ in Figure 3 and the single activation energy $(Q)$ value determined.

Optical micrographs of the medium Mn steel after hot compression to 0.7 strain and quenching to room temperature are shown in Figure 7. Regardless of the hot deformation temperatures, austenite and ferrite were observed without trace of martensite. Moreover, the material did not undergo a tangible phase transformation during hot deformation such that the fraction of ferrite and austenite remained invariant (Figure 8). Therefore, the following analysis of the relationship between the flow curves and the microstructure will not consider phase transformation during deformation.

After hot deformation to 0.7 strain, the dendritic characteristics of austenite are still largely present as a globular morphology. There are signs suggesting that the austenite grains were deformed and pancaked with an orientation perpendicular to the compression direction, particularly revealed in Figure 7(a). No sub-structure in the austenite was observed from the optical images. On the other hand, it is clearly shown in Figure 7 that the ferrite grains are much more refined at all deformation temperatures, implying that ferrite has undergone dynamic recrystallization. The grain size of the ferrite after hot deformation was determined based on the linear intercept method and plotted $v s \ln Z$ in Figure 9, showing an increase with increasing deformation temperatures and decreasing strain rates (lower $Z$ ).

In order to clarify the evolution of the microstructure under hot deformation and to study the effect of the microstructure on the flow curves, samples were hot compressed to different strains $(0,0.1,0.3,0.7)$ at $1273 \mathrm{~K}\left(1000^{\circ} \mathrm{C}\right)$ and $1 \mathrm{~s}^{-1}$, followed by rapid quenching. EBSD mapping was conducted for these hot compressed samples to investigate the hot deformation
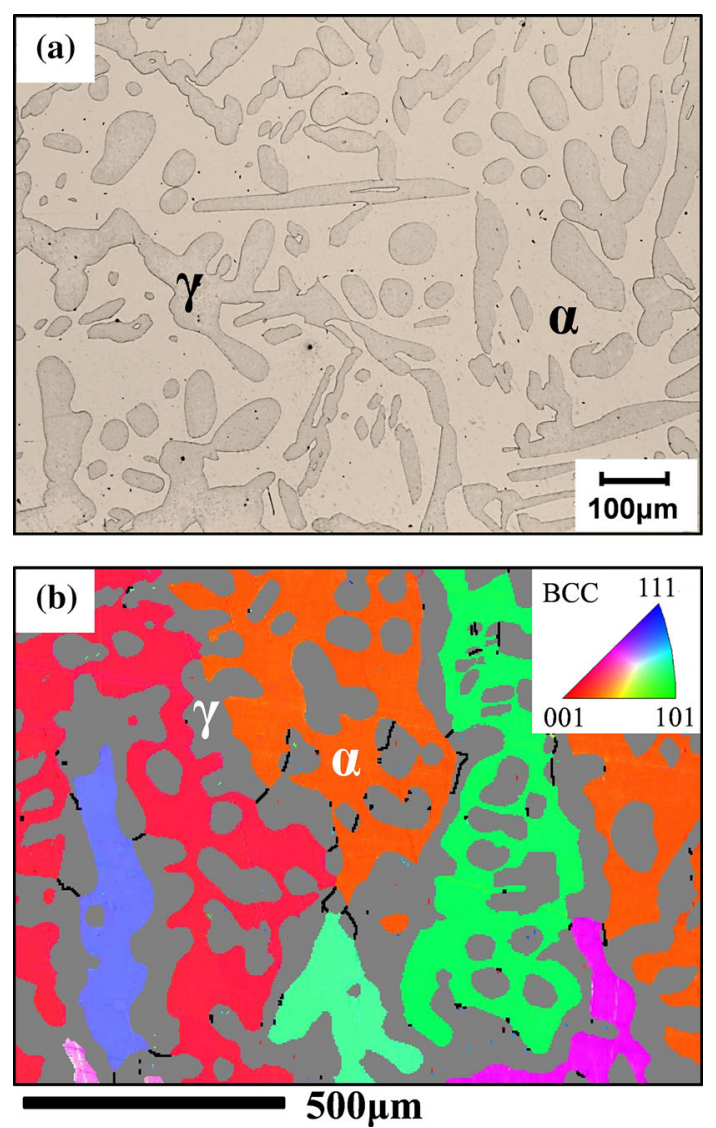

Fig. 5-Microstructure of the as-cast medium Mn steel after homogenization at $1473 \mathrm{~K}\left(1200{ }^{\circ} \mathrm{C}\right)$ for $3 \mathrm{~h}$ followed by water quench: $(a)$ Optical micrograph and (b) EBSD image displaying a phase map of austenite (gray) with grain boundaries and an inverse pole figure (IPF) of ferrite.

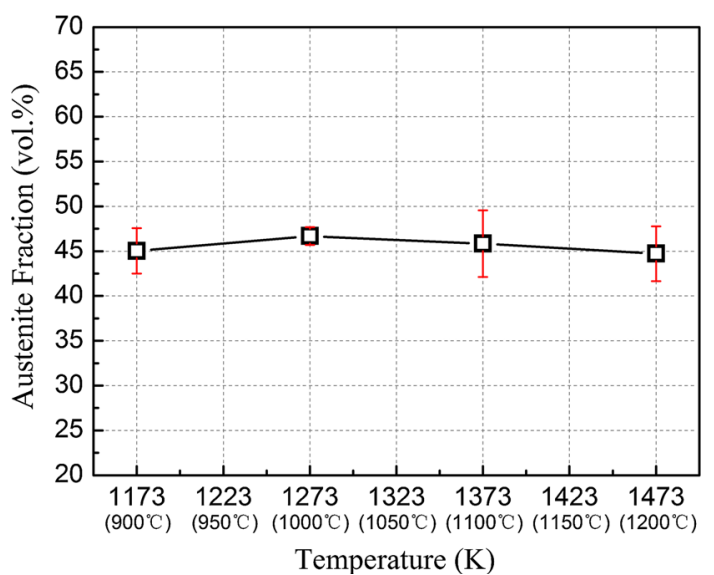

Fig. 6-Austenite fraction of the samples quenched from different deformation temperatures before deformation (measured by OM).

behavior of ferrite and austenite in more detail, and the results are shown in Figure 10. Prior to deformation, as shown in Figures 10(a) and 5(b), most of the austenite dendrites are single crystals, with only a few of them showing high angle boundaries inside. There are no misorientation features in ferrite, which has a grain size 

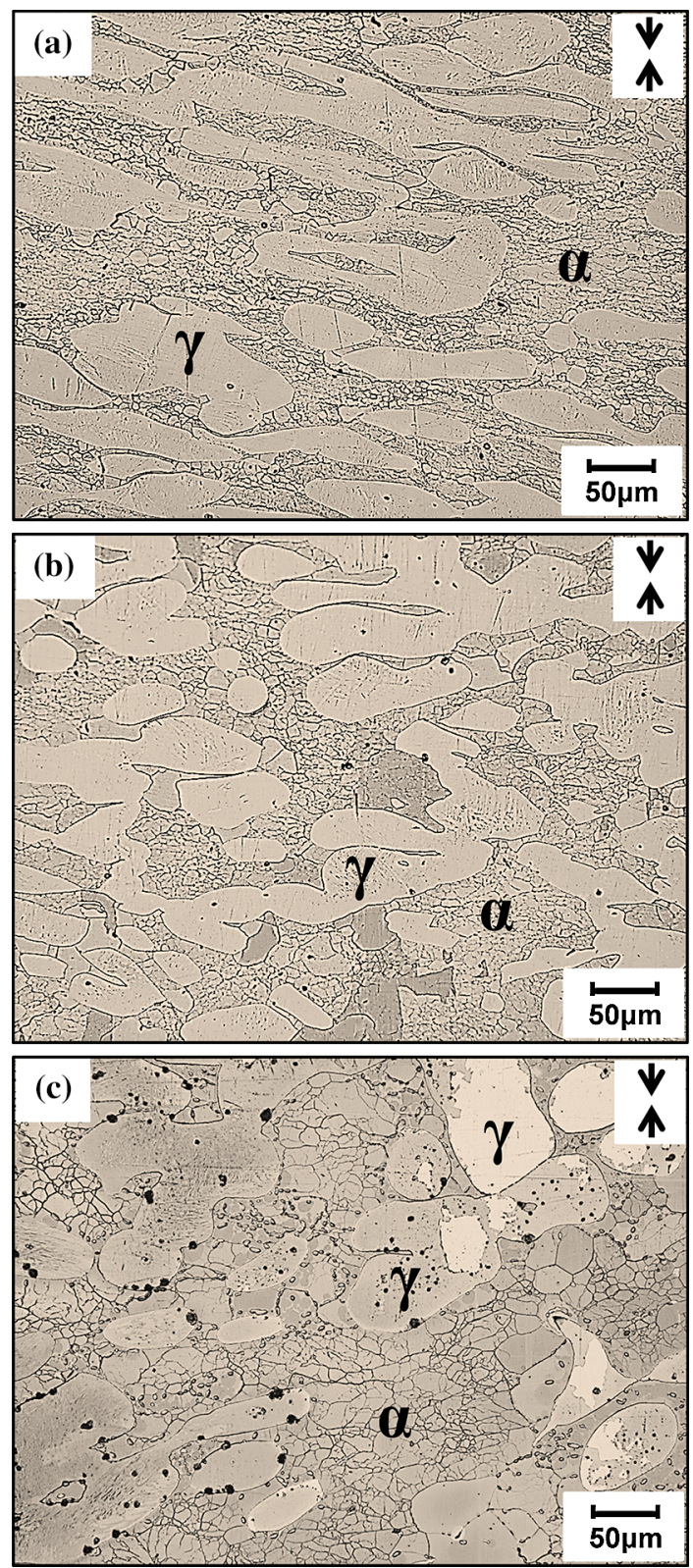

Fig. 7-Optical micrographs of the as-cast medium Mn steel after hot compression to 0.7 strain at $1 \mathrm{~s}^{-1}$ and different temperatures: $(a)$ $1173 \mathrm{~K}\left(900{ }^{\circ} \mathrm{C}\right) ;\left(\right.$ b) $1273 \mathrm{~K}\left(1000{ }^{\circ} \mathrm{C}\right) ;(c) 1373 \mathrm{~K}\left(1100{ }^{\circ} \mathrm{C}\right)$. (The arrows in the images indicate the hot compression direction).

of more than $\sim 500 \mu \mathrm{m}$. Most of the austenite/ferrite interfaces possess the well-known Kurdjumov-Sachs $(\mathrm{K}-\mathrm{S})$ orientation relationship, as shown in Figure 10(a) in which the $\mathrm{K}-\mathrm{S}$ orientation interface boundaries are plotted as thick black lines. After deformation to 0.1 strain (Figure 10(b)), some low angle boundaries form in ferrite, and most of them are located around austenite/ferrite interfaces, indicating a localization of deformation in the vicinity of the interfaces. These low angle boundaries are a sign of ferrite recovery. Some austenite/ferrite interfaces still follow the $\mathrm{K}-\mathrm{S}$ orientation relationship, however, compared with Figure 10(a), the frequency of this kind of interface is reduced. The samples hot deformed to 0.3 and 0.7 strain at $1 \mathrm{~s}^{-1}$ and

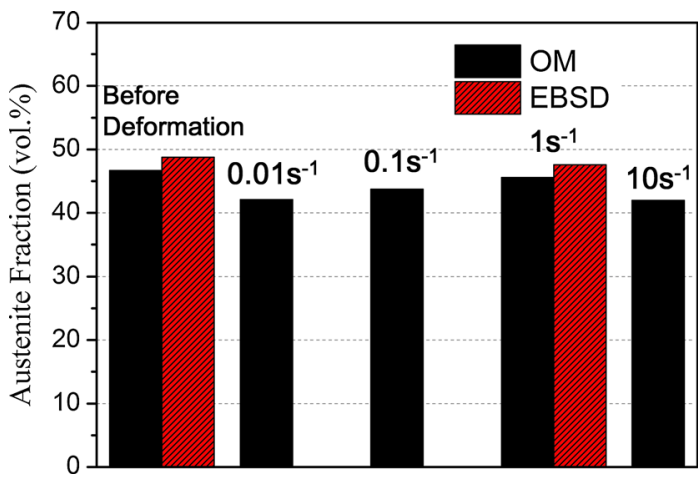

Fig. 8-Austenite fraction of the samples before and after deformation at $1273 \mathrm{~K}\left(1000{ }^{\circ} \mathrm{C}\right)$ and different strain rates (measured by $\mathrm{OM}$ and EBSD), showing a very small austenite fraction change (less than 5 vol pet variation) during deformation. (Similar results have been found for other deformation temperatures and not shown in this paper).

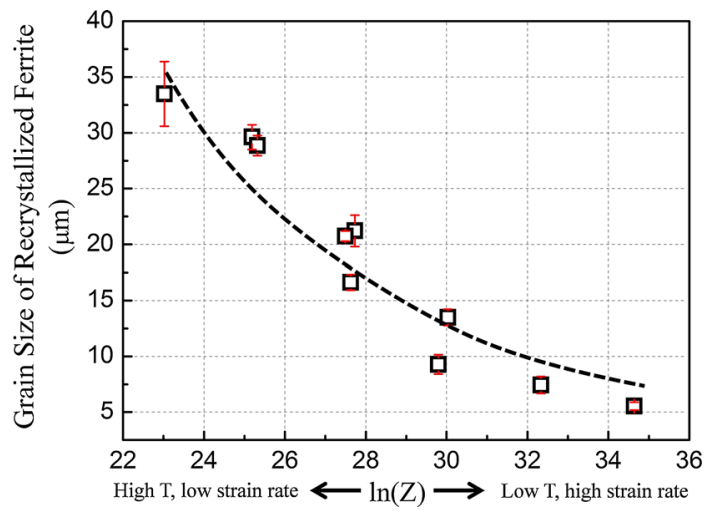

Fig. 9-Effect of deformation temperature and strain rate on the grain size of the recrystallized ferrite.

$1273 \mathrm{~K} \quad\left(1000{ }^{\circ} \mathrm{C}\right)$ have similar characteristics (Figures 10(c) through (g)). In both samples, high angle boundaries form in some austenite grains, which signifies dynamic recrystallization. However, other austenite grains are deformed (i.e., reveal misorientations as shown in Figure 10(e)) without evidence of high angle boundaries, indicating that the critical strain for austenite to undergo dynamic recrystallization has not been reached in these grains; most likely due to improper crystallographic orientations. A large fraction of ferrite has already been recrystallized even at a relatively small strain of 0.3. A complex network of low and high angle boundaries is characterized when the strain is above 0.3 , as shown more clearly in Figure $10(\mathrm{~g})$ (the numbers along ferrite grain boundaries indicate the misorientation angles between ferrite subgrains). Most of the interfaces no longer follow the $\mathrm{K}-\mathrm{S}$ orientation relationship after the sample is deformed to 0.3 strain, and this relationship completely disappears at 0.7 strain. Figure 11 shows the distribution of the deviation from the $\mathrm{K}-\mathrm{S}$ orientation relationship between austenite and ferrite at different deformation stages, which reveals a gradual loss of the $\mathrm{K}-\mathrm{S}$ orientation relationship during straining. 

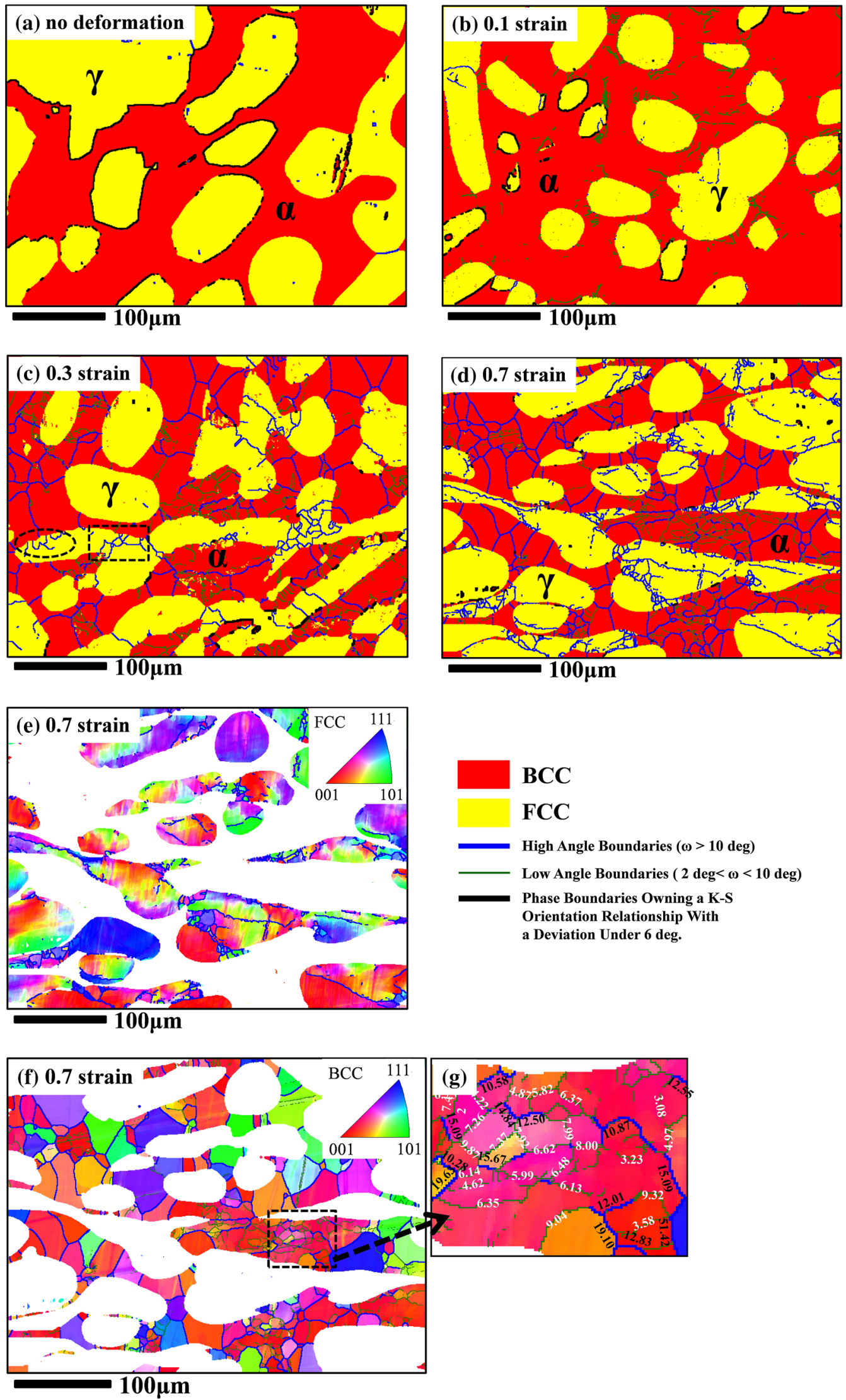

Fig. 10-EBSD images of the specimens hot compressed to different strains at $1273 \mathrm{~K}\left(1000{ }^{\circ} \mathrm{C}\right)$ and $1 \mathrm{~s}^{-1}$ : phase mapping of the specimens $(a)$ without hot deformation, $(b)$ hot deformed to 0.1 strain, $(c)$ hot deformed to 0.3 strain, and $(d)$ hot deformed to 0.7 strain; IPF orientation map of $(e)$ austenite and $(f)$ ferrite of region $(\mathrm{d}) ;(g)$ Detail of IPF showing misorientation angles between ferrite grains. 


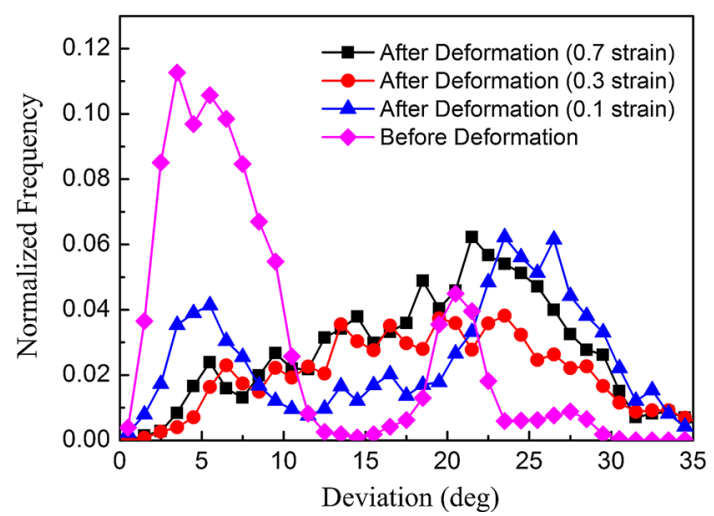

Fig. 11-Distribution of the deviation from the $\mathrm{K}-\mathrm{S}$ orientation relationship between austenite and ferrite at different deformation stages.

\section{DISCUSSION}

\section{A. Microstructure Evolution of the FADP Structure During Hot Deformation}

The initial grain size of ferrite is more than $500 \mu \mathrm{m}$ measured by EBSD. After deformation to strains of 0.3 or higher, recrystallization in ferrite is widespread, and the grain size has decreased significantly. No clear nucleation stage was observed and both low angle and high angle boundaries were revealed in the microstructure, forming a complex network (Figure 10(g)). This supports the literature observations that a high SFE metal can undergo continuous dynamic recrystallization; Cizek and Wynne ${ }^{[15]}$ also classified this softening mechanism in ferrite as 'extended dynamic recovery'. At the early stage of deformation, subgrains with low angle boundaries first form by dynamic recovery in ferrite. During straining, the misorientation between neighboring subgrains gradually increases because of the migration and the merging of low angle dislocation walls, which results in the formation of high angle boundaries at higher strains. This theory was also supported by Schmidt ${ }^{[23]}$ who found an increase of the subgrain misorientation angle in a ferritic stainless steel during high temperature straining. Glover and Sellars ${ }^{[9]}$ proposed that there was a transition from dynamic recrystallization to dynamic recovery of ferrite based on the value of Zener-Hollomon parameter $(Z)$, and they found that ferrite was dynamically recrystallized when $\mathrm{Z}$ parameter was smaller than $\sim 10^{15} \mathrm{~s}^{-1}$ for a zone-refined iron with a grain size of $\sim 800 \mu \mathrm{m}$. In this study, the $Z$ value is ranging from $\sim 10^{10}$ to $10^{15} \mathrm{~s}^{-1}$, which is in a good agreement with Glover's work.

There are different opinions as to whether austenite undergoes dynamic recrystallization when deformed under the existence of ferrite ${ }^{[15,17,18]}$ but only a few researchers have presented a detailed austenite microstructure. In the present work, dynamic recrystallization of austenite in the dual-phase medium Mn steel was clearly observed for the first time (Figures 10(c) and (d)). Initial high angle boundaries play a critical role in 'conventional' discontinuous dynamic recrystallization, because they provide nucleation sites for new grains. ${ }^{[8]}$ In the present study, when austenite

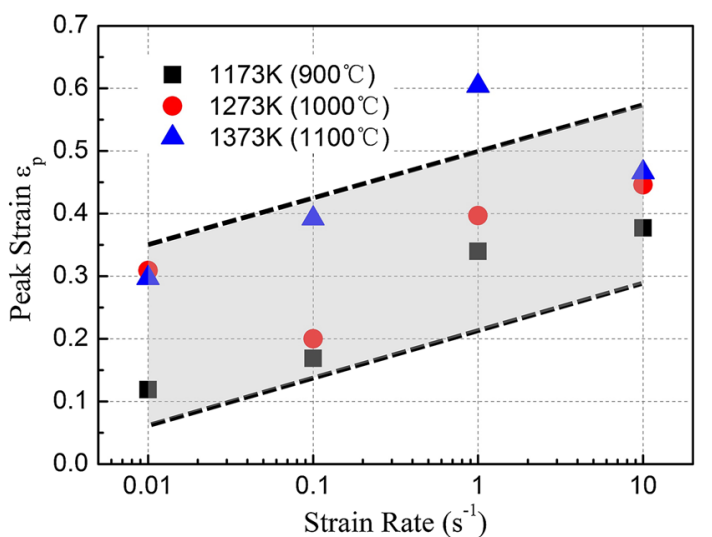

(a)

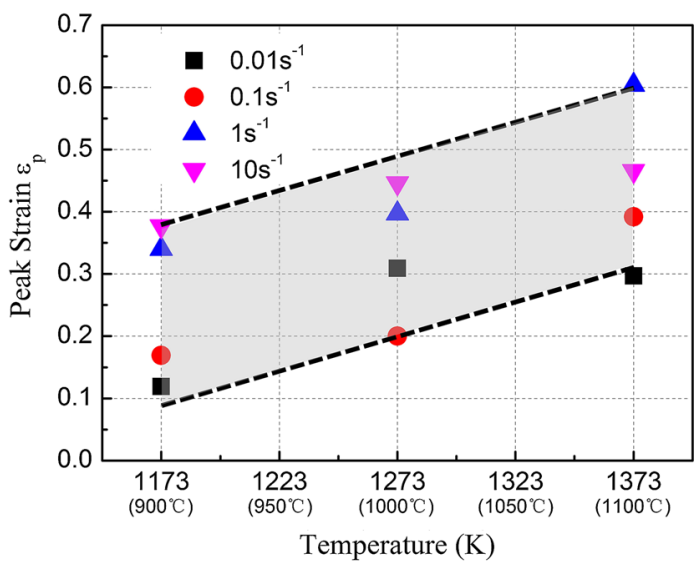

(b)

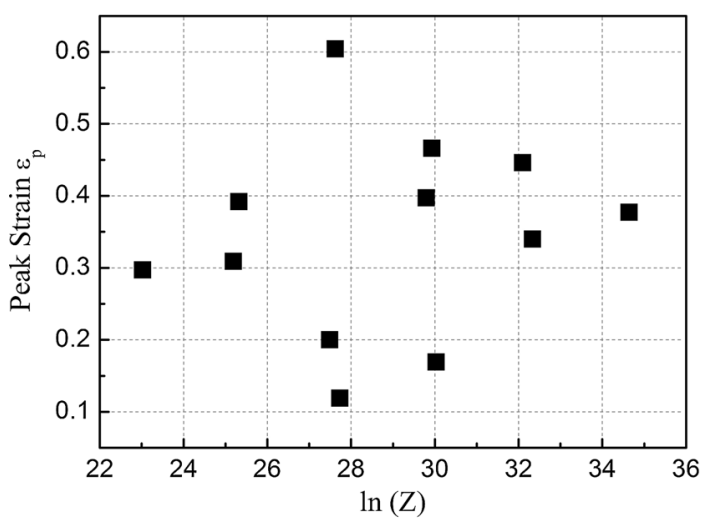

(c)

Fig. 12-Peak strain of the flow curves as a function of $(a)$ strain rate, (b) deformation temperature, and (c) $\mathrm{Z}$ parameter.

starts to recrystallize (at 0.3 strain), there are signs that new DRX grains originate at initial grain boundaries and austenite/ferrite interfaces (marked in a rectangular and an elliptic frames in Figure 10(c), respectively). It might be expected that dislocation activity would be the heaviest at the austenite/ferrite interfaces since there should be considerable plastic flow and crystallographic mismatch at these regions. For instance, the EBSD phase map of the specimen deformed to 0.1 strain (Figure 10(b)) illustrates increased activities at the austenite/ferrite interfaces through the 
appearance of low angle ferrite boundaries intersecting the interfaces. However, only a few interfaces are included as new nucleation sites, even in the sample deformed at higher strain (Figure 10(d)). On the other hand, as mentioned in Section III-B, since there are only a few austenite grain boundaries in the undeformed structure, it is a little unexpected to observe such a high level of recrystallization inside austenite grains, especially for the sample deformed to 0.7 (Figure $10(\mathrm{~d})$ ). It is possible that other high angle boundaries, such as deformation bands or deformation twins, could also participate in the austenite recrystallization, but there is little sign of such features.

\section{B. Flow Curves}

As described in Section III-A, the flow curves of the as-cast medium Mn steel under hot compression tests have the characteristics of a discontinuous yielding, followed by a weak working hardening to a peak and a subsequent mild softening stage. These curves differ somewhat from the "conventional" flow curves of single-phase materials, which show a monotonic-parabolic work hardening to either a steady-state plateau (single-phase ferrite) or a broad peak followed by a softening stage (single-phase austenite). This mild softening stage in the $3 \mathrm{rd}$ part of the flow curves is attributed to the restoration of ferrite and austenite, which will be discussed in detail later. However, it was claimed by Mirzadeh ${ }^{[24]}$ that the softening could also be due to adiabatic heating of the samples during deformation at high strain rates. In this work, the measured temperature increase during deformation was quite small: about $10 \mathrm{~K}$ at $10 \mathrm{~s}^{-1}$ strain rate and lower than $3 \mathrm{~K}$ at lower strain rates, regardless of the test temperatures. Note that this softening stage also exists at the lowest strain rate, which does not have a measureable temperature increase during deformation. This indicates that the adiabatic heat is not the main reason for the drop of the flow curves.

There are two softening mechanisms observed in the as-cast medium Mn steel during hot deformation: dynamic recrystallization of austenite and continuous dynamic recrystallization of ferrite. It is difficult to quantify the relative contributions of these mechanisms to the overall softening. Some researchers studied the hot deformation behavior of duplex stainless steels and believed that the softening stage was mainly a result of austenite dynamic recrystallization. ${ }^{[14,15]}$ Some of the microstructural characteristics in the present study seem to support this idea. When the material is hot deformed to strains before the peak (e.g., 0.3 strain, as shown in Figure 10(c)), a large number of high angle boundaries has already been formed in the ferrite. It is thus possible that the DRX of ferrite is more or less completed before the peak strain, and does not contribute strongly to the softening of the flow curves.

When dynamic recrystallization occurs, the strain corresponding to the peak stress (peak strain $\varepsilon_{\mathrm{p}}$ ) of the flow curves can be used to gauge the kinetics of DRX. ${ }^{[9]}$ Generally in materials possessing a single phase at hot working temperatures, the peak strain increases steadily with increasing $Z$ (lower temperatures and higher strain rates), ${ }^{[25]}$ because lower temperatures decrease the mobility of boundaries and the rearrangement rate of dislocations. Similarly, higher strain rates provide shorter times for boundary migration and dislocation reconfiguration, resulting in a delay of DRX. In the present study, the peak strain of the flow curves is plotted as a function of strain rate, deformation temperature, and $Z$ parameter (Figure 12). As shown in Figure 12(a), the peak strain $\left(\varepsilon_{\mathrm{p}}\right)$ increases with increasing strain rates, which implies that the DRX of austenite initiates later at higher strain rates. However, it also increases with deformation temperatures (Figure 12(b)), indicating that the DRX of the austenite starts earlier at lower temperatures, which is the opposite behavior of single-phase materials. The combined effect of strain rate and deformation temperature on austenite DRX kinetics results in an unsystematic relationship between peak strain and $Z$ (Figure 12(c)). The observed effect of hot deformation temperature on the peak strain of flow curves can be explained by the strain partitioning between ferrite and austenite and the DRX kinetics of the two phases. Ferrite is believed to be softer than austenite at the same hot deformation temperatures, thus it accommodates most of the strain in the early stages of plastic deformation. ${ }^{[14,26,27]}$ Then strain transfer from ferrite to austenite takes place during further deformation, which partly contributes to the mild work hardening part in the flow curves. Dislocations in the austenite grains gradually accumulate during this time, and DRX initiates when the critical dislocation density is reached. This strain partitioning idea has been widely accepted and proved experimentally in the literature. ${ }^{[26,27]}$ However, with increasing temperatures, the extent of ferrite recrystallization increases for a given strain. It is reasonable to assume that an increase in ferrite softening will trigger a decreasing load transfer from ferrite to austenite at the same time (smaller work hardening rate in the 2 nd part of the flow curves, as shown in Figure 4), which will delay the DRX of austenite to larger applied strains.

Another characteristic of the flow curves is the discontinuous yielding at the beginning of plastic deformation, which is also found in duplex stainless steels by several researchers. ${ }^{[14,18,26]}$ Several people proposed that this discontinuous yielding was a result of the well-known Kurdjumov-Sachs $(\mathrm{K}-\mathrm{S})$ orientation relationship between ferrite and austenite in as-cast steels. ${ }^{[16,18,26]}$ The deformation misfit between ferrite and austenite in the initial stage must be accommodated at the phase boundaries, which may result in the interface sliding. This sliding is believed to be seriously impeded by the semi-coherent interface, which forms due to the $\mathrm{K}-\mathrm{S}$ orientation relationship. This produces an extra strengthening effect that must be overcome at the start of deformation. The $\mathrm{K}-\mathrm{S}$ orientation relationship will gradually diminish during deformation, ${ }^{[18,28]}$ weakening the material and leading to the small drop that defines discontinuous yielding. However, Duprez ${ }^{[14]}$ believed that this small drop was driven by the intense softening of ferrite at early stages since the deformation was mainly accommodated by ferrite at the beginning. In the current work, samples hot compressed to 0.1 strain at $1273 \mathrm{~K}\left(1000{ }^{\circ} \mathrm{C}\right)$ and $1 \mathrm{~s}^{-1}$ were examined, as shown in 


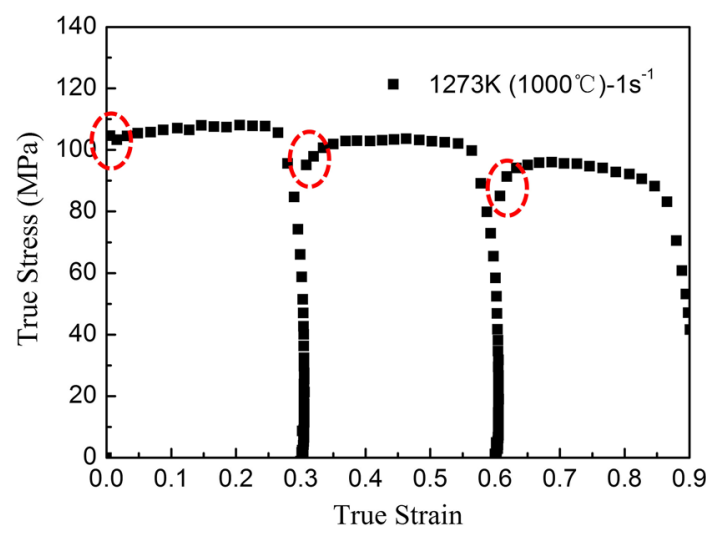

Fig. 13-Stress-strain curve determined by hot torsion tests at $1273 \mathrm{~K}\left(1000{ }^{\circ} \mathrm{C}\right)$ and $1 \mathrm{~s}^{-1}$.

Figure 10(b). The strain corresponding to the discontinuous yielding at this condition is lower than 0.05 . Only a few subgrains were observed in the ferrite at this condition, which reveals that this discontinuous yielding cannot be derived from the softening of ferrite. On the other hand, as noted in Section III-B, it is clear that most of the interfaces exhibit the $\mathrm{K}-\mathrm{S}$ orientation relationship before deformation, and this relationship diminishes gradually upon further deformation. Therefore, this evolution of the interphase boundaries is believed to lead to the discontinuous yielding in the flow curves.

In order to confirm the influence of this $\mathrm{K}-\mathrm{S}$ orientation relationship on the discontinuous yielding, hot torsion tests were carried out. The Von Mises equivalent stress and strain were converted based on measured torque and torsion angle. ${ }^{[13]}$ From the flow curve determined by hot torsion tests (Figure 13), the discontinuous yielding is obvious in the first deformation, however, it disappears and transforms to a parabolic work hardening curve in the second and third pass where most of the ferrite/austenite interfaces no longer follow the $\mathrm{K}-\mathrm{S}$ orientation relationship. This supports the dominating effect of the $\mathrm{K}-\mathrm{S}$ orientation relationship between ferrite and austenite on the initial yielding and the shape of the flow curves.

\section{CONCLUSIONS}

In the present study, the hot deformation behavior of an as-cast Fe-0.2C-10 Mn-3Si-3Al medium $\mathrm{Mn}$ steel was studied mainly by hot compression tests at temperatures ranging from $1173 \mathrm{~K}$ to $1373 \mathrm{~K}\left(900{ }^{\circ} \mathrm{C}\right.$ to $1100{ }^{\circ} \mathrm{C}$ ) and different strain rates. Analysis of the flow curves and microstructure led to the following conclusions:

1. An FADP microstructure containing 45 pct (volumetric) austenite was obtained in the as-cast medium Mn steel following homogenization. The initial microstructure was stable during reheating to $1473 \mathrm{~K}\left(1200^{\circ} \mathrm{C}\right)$, subsequent cooling to different deformation temperatures, and upon continuous hot deformation.
2. The flow curves of the medium Mn steel demonstrated common features at all examined deformation temperatures and strain rates, and were characterized by a discontinuous yielding, followed by a mild work hardening to a peak and a subsequent weak softening stage.

3. Two restoration processes took place during deformation: dynamic recrystallization of austenite and continuous dynamic recrystallization of ferrite. Continuous recrystallization of ferrite was almost completed before the peak of flow curves, whereas DRX of austenite was believed to be the main reason for the softening following the peak. The DRX kinetics of austenite and ferrite was related to the strain partitioning between the two phases during hot deformation.

4. The Kurdjumov-Sachs $(\mathrm{K}-\mathrm{S})$ orientation relationship between ferrite and austenite existed in the undeformed samples, and this relationship gradually weakened during deformation. This resulted in a discontinuous yielding showing on the flow curves.

\section{ACKNOWLEDGMENTS}

One of the authors (Binhan Sun) is grateful to the China Scholarship Council (CSC) and the McGill Engineering Doctoral Award (MEDA) program for granting a period of scholarship support.

\section{REFERENCES}

1. D.K. Matlock and J.G. Speer: in Microstructure and Texture in Steels, A. Haldar, S. Suwas, and D. Bhattacharjee, eds., Springer, New York, 2009, pp. 185-205.

2. Y.K. Lee and J. Han: Mater. Sci. Technol., 2015, vol. 31, pp. 843-56.

3. B.C. De Cooman, P. Gibbs, S. Lee, and D.K. Matlock: Metall. Mater. Trans. A, 2013, vol. 44, pp. 2563-72.

4. A. Dumay, J.P. Chateau, S. Allain, S. Migot, and O. Bouaziz: Mater. Sci. Eng. A, 2008, vols. 483-484, pp. 184-87.

5. E. Pereloma and D.V. Edmonds: Phase Transformations in Steels. 1st ed., vol 2, Woodhead Publishing Ltd., Philadelphia, PA, 2012, pp. 213-246.

6. H. Aydin, E. Essadiqi, I.H. Jung, and S. Yue: Mater. Sci. Eng. A, 2013, vol. 564, pp. 501-08.

7. D.W. Suh, S.J. Park, T.H. Lee, C.S. Oh, and S.J. Kim: Metall. Mater. Trans. A, 2010, vol. 41A, pp. 397-408.

8. F.J. Humphreys and M. Hatherly: Recrystallization and Related Annealing Phenomena, 2nd ed., Elsevier Ltd., 2004, pp. $415-50$.

9. G. Glover and C. Sellars: Metall. Trans., 1973, vol. 4, pp. 765-75.

10. S.V.S.N. Murty, S. Torizuka, K. Nagai, T. Kitai, and Y. Kogo: Scripta Mater., 2005, vol. 53, pp. 763-68.

11. M.R. Barnett, G.L. Kelly, and P.D. Hodgson: Metall. Mater. Trans. A, 2002, vol. 33A, pp. 1893-1900.

12. J. Baczynski and J.J. Jonas: Metall. Mater. Trans. A, 1998, vol. 29A, pp. 447-62.

13. G.E. Dieter, H.A. Kuhn, and S.L. Semiatin: Handbook of Workability and Process Design. 1st ed. ASM international, 2003, pp. 35-116. 
14. L. Duprez, B.C. De Cooman, and N. Akdut: Metall. Mater. Trans. A, 2002, vol. 33A, pp. 1931-38.

15. P. Cizek and B.P. Wynne: Mater. Sci. Eng. A, 1997, vol. 230, pp. 88-94.

16. O. Balancin, W.A.M. Hoffmann, and J.J. Jonas: Metall. Mater. Trans. A, 2000, vol. 31, pp. 1353-64.

17. G. Fan, J. Liu, P. Han, and G. Qiao: Mater. Sci. Eng. A, 2009, vol. 515 , pp. $108-12$.

18. A. Iza-Mendia, A. Pinol-Juez, J.J. Urcola, and I. Gutiérrez: Metall. Mater. Trans. A, 1998, vol. 29A, pp. 2975-86.

19. H. Farnoush, A. Momeni, K. Dehghani, J.A. Mohandesi, and H. Keshmiri: Mater. Des., 2010, vol. 31, pp. 220-26.

20. C.M. Sellars and W.J.M.G. Tegart: Mem. Sci. Rev. Met., 1966, vol. 63 , pp. $731-46$.

21. J.M. Cabrera, A. Mateo, L. Llanes, J.M. Prado, and M. Anglada: J. Mater. Process. Technol., 2003, vols. 143-144, pp. 321-25.
22. A.S. Hamada, L.P. Karjalainen, and M.C. Somani: Mater. Sci. Eng. A, 2007, vol. 467, pp. 114-24.

23. C.G. Schmidt, C.M. Young, B. Walser, R.H. Klundt, and O.D. Sherby: Metall. Trans. A, 1982, vol. 13, pp. 447-56.

24. H. Mirzadeh, A. Najafizadeh, and M. Moazeny: Metall. Mater. Trans. A, 2009, vol. 40A, pp. 2950-58.

25. W. Roberts and B. Ahlblom: Acta Mater., 1978, vol. 26, pp. 801-13.

26. A.M. Jorge Júnior, G.S. Reis and O. Balancin: Mater. Sci. Eng. A, 2011, vol. 528, pp. 2259-64.

27. S. Spigarelli, M. El Mehtedi, P. Ricci, and C. Mapelli: Mater. Sci. Eng. A, 2010, vol. 527, pp. 4218-28.

28. G. Martin, S.K. Yerra, Y. Bréchet, M. Véron, J.D. Mithieux, B. Chéhab, L. Delannay, and T. Pardoen: Acta Mater., 2012, vol. 60, pp. $4646-60$. 